\title{
China's effective measures in fighting against COVID-19 and pollutant changes in Wuhan during corresponding periods
}

Fang Zhang ( $\sim$ zhangfang@pric.org.cn )

Polar Research Institute of China https://orcid.org/0000-0002-0300-8273

\section{Yi Han}

Durham University

\section{Bailin Cong}

First Institute of Oceanography State Oceanic Administration: First Institute of Oceanography Ministry of Natural Resources

\section{Research Article}

Keywords: Strategic positions, major airborne pollutants, COVID-19 variants, effective policies, sustainable societies

Posted Date: November 15th, 2021

DOI: https://doi.org/10.21203/rs.3.rs-1001459/v1

License: (c) (i) This work is licensed under a Creative Commons Attribution 4.0 International License. Read Full License 


\section{Abstract}

The $\delta$ - and $\lambda$-variants of COVID-19 are blowing to globle economy, human life and health. The variants put the world in a harsher state. Lockdown is powerful in stopping the spread and infection. We evaluate the lockdown impact on $\mathrm{NO}_{2}, \mathrm{SO}_{2}, \mathrm{O}_{3}, \mathrm{PM}_{2.5}$ and $\mathrm{PM}_{10}$ in Wuhan, which reported the first COVID-19 case. Data before, during and after blokade in year 2020 were all analyzed. Lockdown significantly decreased four of the five pollutants. The decreasing reasons are discussed in social policies, people's living habits and Chinese characters. Wuhan is a transportation hub in central China. Viruses spread through it to all over the country. Although COVID-19 mainly bring bad social effects, people get chance to rethink the value of life: We should sustainablely develop and pursuing spiritual instead of excessive material enjoyment. These ultimately built more stable societies and benefit mankind itself.

\section{Introduction}

As a megacity in the middle and lower reaches of the Yangtze River, Wuhan is the largest metropolis in central part with a strategic position and one of the seven central cities in China [1]. Known as the thoroughfare of nine provinces, Wuhan is rich in freshwater, which account for about a quarter of its urban area. There are dozens of fresh water lakes besides the Yangtze River and the Hanshui River [1].

Wuhan reported the first COVID-19 case globally on 30th December 2019 [2] and throughed inter-city travel bans and stricted self-isolation [2] from 23rd January 2020 to stop the virus spread [3]. COVID-19 and its variants have led to more than 205.567 and 16.687 million reported and existing cases to 12th August 2021 [4]. The viruses seriously blow global economy and social stability [5,6]. Nevertherless, they provides good changces for medicical and enviromental studies $[7,8]$.

Many studies were conducted on air pollutants during the COVID-19 outbreak [3,9]. These studies usually refer levels of pollutants during the lockdown period and comprehensive analysis before, during and postlockdown are yet to be available [3]. As Wuhan reported the first global COVID-19 case and had the longest lockdown time in China [10], it offered an optimal chance to study the air pollutants' changes in a long time series. We studied five major air pollutants i.e., $\mathrm{NO}_{2}, \mathrm{SO}_{2}, \mathrm{O}_{3}, \mathrm{PM}_{2.5}$ and $\mathrm{PM}_{10}$. They are mainly produced by traffic and heavy industry [11]. $\mathrm{NO}_{2}$ produces photochemical smog and short-term exposure of $\mathrm{SO}_{2}$ increases death rate [12]. Ground-level $\mathrm{O}_{3}$ forms when gases composed of nitrogen and oxygen (NOx) and volatile organic compounds (VOCs), interact in the presence of sunlight $[1,13]$. Surface $\mathrm{O}_{3}$, forming in agriculture and forestry around large cities, correlates with season and meteorology [9]. $O_{3}$ is hurmful to human health, vegetation and wildlife [5]. It accounted for $28 \%$ of all respiratory deaths in 2010 [14]. $\mathrm{PM}_{2.5}$ directly cause human death as its acidity penetrates the lower respiratory tract [15]; some toxic gases and pathogenic microorganisms attaching to PM aggravat harm to human health [15]. What's worse is short term exposure of all the above polutants increases COVID-19 infection [16].

We studied concentration changes of all the five pollutants in Wuhan of year 2020 including before and during the lockades, and make comparisons with years of 2019 and 2020 as general cases from human 
interfernce. This study fills the blank of air pollutants' comparison in different periods of long time series in terms of research. It also provides appropriate advices among economic growth, enviromental protection, and fighting aginst COVID-19 and its variants. These provide a theoretical basis for building globally healthy societies, which ultimately benefit mankind itself.

\section{Methods}

\subsection{Data collection}

Daily average concentrations of the five pollutants were collected from 1st January to 25th March 2020 in Wuhan. the corresponding average data of year 2018 and 2019 were compared with the ones of year 2020. The daily data of the polutants $\left(\mathrm{NO}_{2}, \mathrm{SO}_{2}, \mathrm{O}_{3}, \mathrm{PM}_{2.5}\right.$ and $\left.\mathrm{PM}_{10}\right)$ were provided by Wuhan Municipal Bureau of Ecology and Environment [17], and average values were used for each day. The enviromental data set from Wuhan contains 23,62 and 27 values, respectively, before, during and after the lockdown period in year 2020 .

\subsection{Data Processing}

Two comparisons were done: First, comparison before lockdown period (1st Jan-23rd Jan) and during lockdown period (24th January -25th March) in year of 2020. Second, comparison data from the same dates but of different years (average data of 2018-2019 and data of 2020). One-way ANOVA, Nonmetric Multidimensional scaling (NMDS) analysis and cluster analysis were used to process the data. SPSS (SPSS Inc., Chicago, USA) was used to do one-way ANOVA; whereas R was used to do cluster analysis (version 3.4.1). The calculation of the Air Quality Sub-Index (AQI) for Air Pollutant (IAQIP) measures the total quality of air are as followed:

$$
A Q I=\max \left(I_{1}, I_{2}, \ldots, L_{n}\right) ; I A Q I_{P}=\frac{I_{\text {high }}-I_{\text {low }}}{C_{\text {high }}-C_{\text {low }}}\left(C_{P}-C_{\text {low }}\right)+I_{\text {low }}
$$

$C_{P}$ : the concentration of pollutant $p ; C_{\text {low }}$ : the concentration breakpoint that is $\leq C_{P}$

$C_{\text {high }}$ : the concentration breakpoint that is $\geq C_{P} ; I_{\text {low }}$ : the index breakpoint corresponding to $C_{\text {low }} ; I_{\text {high }}$ : the index breakpoint corresponding to $C_{\text {high }}$.

\section{Results}

Concentration changes of major pollutants in wuhan before and duiring the Covid-19 lockdown periods in year 2020 
Generally, concentrations were in order of $\mathrm{PM}_{2.5}>\mathrm{PM}_{10}>\mathrm{NO}_{2}>\mathrm{O}_{3}>\mathrm{SO}_{2}$ (Fig. 1 and Fig. 1 in Supplimentary Materials (Fig. S1)) $\mathrm{PM}_{2.5}, \mathrm{PM}_{10}, \mathrm{NO}_{2}$ had similar changing trends, which is almost opposite to the trend of $\mathrm{O}_{3}$ (Fig. S1). The concentrations of $\mathrm{SO}_{2}$ were relatively steady with similar changing trand of surface $\mathrm{O}_{3}$ (Fig. 1 and Fig. S1). Little peeks appeared during the late time of the Chinese Spring Festival (Fig. 1). Lockdown decreased their concentrations, except for that of $\mathrm{O}_{3}$ with a growing trend. $\mathrm{NO}_{2}, \mathrm{PM}_{2.5}$ and $\mathrm{PM}_{10}$ decreased immediately after the lockdown (Fig. 1). There were very significant changes to all the five pollutants before and during the lockdown period $(p<0.01$ or 0.001$)$ (Fig. S1). Large increasing concentrations of $\mathrm{O}_{3}(117 \%)$ accomponied by very significant decrease of $\mathrm{NO}_{2}$ (32\%; $p=-0.004)$, significant decrease of $\mathrm{PM}_{2.5}(34 \% ; p=-0.046)$, and silightly decrease of $\mathrm{PM}_{10}(17 \% ; p=$ -0.23). Cluster analysis and NMDS (Fig. S2) shows that $\mathrm{PM}_{2.5}, \mathrm{PM}_{10}$ and $\mathrm{NO}_{2}$ has similar sources [18]. Comparatively, source of $\mathrm{SO}_{2}$ is unique. Lockdown improved the AQI, which worsen again when the city when the city is reopened (Fig. 2).

\section{Comparisons between COVID-19 and non-COVID-19 periods}

All pollutants varied dramatically in 2020 compared with the same period in 2018 and 2019, especially during the COVID-19 lockdown period (Fig.3). The average decreasing rate of $\mathrm{SO}_{2}, \mathrm{NO}_{2}$, $\mathrm{PM}_{2.5}, \mathrm{PM}_{10}$, and $\mathrm{O}_{3}$ were $19 \%, 46 \%, 32 \%, 23 \%$ and $-26 \%$, respectively, before and duiring the lockdown periods. So, the lockdown policy indeed altered all the pollutant concentrations. Concenquently, closing factories and reducing usage of motor vehicles are effective ways to control most pollutants except for $\mathrm{O}_{3}$.

\section{Discussion}

\subsection{Effectiveness of lockdown policy respond to diffusion of COVID-19}

COVID-19 and its variants still brings bad effects on human life and health [7], economy and society [7] after more than one and half years science its firt reported case in Wuhan. There has been lots of variants, such as $\alpha-, \beta-, \gamma-\delta, \varepsilon-, \lambda$-strains, etc.[19,20]. The spread and infection rates of $\delta$ (plus) -and $\lambda$ variants are more serious than the original ones. They are putting the world in a harsher state by bringing more deaths and severe cases. $\delta$-variant was first found in Indian on 11th june 2020 and has been found in more than 130 countries. It has put Europe back on "war footing" [21]. $\delta$-variant is contagious with higher speed and short latent period. The proportion of $\delta$-variant is more and more in the COVID-19 [22] and can induced one more time death than other variants [20]. Firstly detected in Argentina on November $82020, \lambda$-variant with a simultaneous increase in infectivity and immune resistance has found in more than 30 countries [24]. More and more aggrassive variants will be found as because of the rapid mutation nature of viruses. However, the existing vaccines are still effective against the new COVID-19 variants and can reduce rate of severe cases and deaths $[23,25]$. More than 1.1 billion doses of vaccines have been 
administered on the Chinese mainland by 26th July 2021 [23]. Normally two shots are given to stop the infection, but a booster shot has begun to deal with these more aggressive viruses [24].

The lockdown policy with mask wearing is effective on stopping spread of the virus. lockdown policies including city-blocking and factory-shutdown could reduce the emission of air pollutants from transport and production $[6,27]$. As there were seldom heavy industry and traffic, enviroment during the lockdown peirod could be as basline without big human interference [3]. It is good to natural enviroments, but people have to be blocked at home or somewhere else. They are unable to go out for work or communicate with others face to face, and living materials are limited. This may bring anxiety and depression to some people [28] and increase social instability [7]. However, although China was seriously suffered from the virus, it responded quickly and effectively. The Chinese government took several steps to fight against the viruses. First, stopped traffic with latent infectivity and isolated suspected infection people. Second, disinfected, weared masks and kept enough distance. Third, banned parties, and asked people to eat at home with public chopsticks. Fourth, quickly set up enough health care stations and mobilized health care workers across the country to help COVID-19 patients everywhere. Fifth, tested nucleic acids ASAP to confirm the potential cases. Wuhan launched nucleic acid testing for all staff on 3rd August 2021. This got maximum identification of virus carriers, especially asymptomatic infected people [23]. Sixth, worked overtime to develop vaccines and quickly distributed them free of charge across the whole country. All these measures are effective in protecting on human life and natural enviroment and made China fast block the spread of the virus and became the only country with positive economic growth in year 2020 although with a vast area and a large population. This undoubtedly reflects superiority of the system, Chinese kindness and obedience to orders in pulling together to get through the tough times. All the measures still work in fighting against $\delta, \gamma$-and other new potential variants in the future. The COVID-19 outbreak has hit the world, especially with serious impact on human life and the world economy. Nevertheless, it also provided precious chances for people to rethink the value of life: We should sustainablely develop and pursuing spiritual instead of excessive material enjoyment. This can sustain a good natural enviroment and help build sustainable socities [6,7]. The earth is our only home, and we are all in the same boat. We should work together to fight against the viruses and protect the earth environment. It can sustain a healthy living enviroment and the ultimate benefit is human beings.

\subsection{Changes of major pollutants in Wuhan compared with other cities in the world duiring COVID-19}

Air pollution can increase COVID-19 incidence and deaths [4,9]. Released from tailpipe, $\mathrm{NO}_{2}$ and $\mathrm{PM}_{2.5}$ increases the risk of lung infections [4,12]. Besides, $\mathrm{NO}_{2}$ may be an important trigger of mental disorders [29] and acidity of $\mathrm{PM}_{2.5}$ penetrates the lower airways linking to respiratory and cardiovascular disease $[4,28]$. $\mathrm{SO}_{2}$ mainly from the heavy industry with fossil as fuels $[1,28]$. Whereas, $\mathrm{NO}_{2}, \mathrm{PM}_{2.5}$ and $\mathrm{PM}_{10}$ in wuhan were from similar sources, including both heavy industry and traffic. This is different from those in Shanghai (Fig. S3): PM were mainly from the north of Yangzi Delta area [1,30]. 
Comparatively, Shanghai did better in controling all the five air pollutants, which sharply decreased compared with those in Wuhan (Fig. S3). It's worth noting that $\mathrm{O}_{3}$ also showed a decreasing rate of $46 \%$. Comaratively, $\mathrm{O}_{3}$ in wuhan increased by $26 \%$. It's worth noting that surface $\mathrm{O}_{3}$ is always a serious pollutant in developing contries compared with those in the USA [14]. Decreasing concentration of $\mathrm{NO}_{2}$ $(45 \%)$ in Wuhan is lower than those (64\%) in Shanghai (Fig. S3), and Delhi $(60 \%)$ and Mumbai (78\%) in Indian [1], but higher than other Chinese cities (16-38\%) [6,31], most cities in Spain (30\%) [32], the South East of the UK (38\%) [33] and Almaty while (35\%) in Kazakhstan [34].

Generally, the controlling of air major pollutants in Wuhan cannot be lasted for long when the city was unlocked reflected by the increasing AQI (Fig. 3). Besides the reopening of some factories and unlimitation of traffic, its location is another important reason. Wuhan is a transportation hub in central China, pollutants can reach there from regions around it. So, Wuhan did well in controlling the viruses and pollutants with consideration of its location.

\section{Conclusion}

Covid-19 is always bringing serious effect on humen's world, especially with explosures of $\delta$ - and $\lambda$ variants. Lockdown is proved to be effective in stopping spread of virus. China has been taking six effective measures, including stopping non-necessary traffic and face to face communications, timely nucleic acid testing and isolations, wearing masks, strict disinfections, using public chopsticks, uniting against the epidemic in the whole contry, and providing free vaccination with the biggest efforts. Lockdown policy also works well in promopting air qualities. Wuhan survived in the virus attack and provided a good opportunity for environmental research in a long time series. Besides $\mathrm{O}_{3}$, other four air pollutants all significantly decreased during the blockade. Wuhan did well in controlling both pollutants and viruses given its central transportation position in China. People get chance to rethink the value of life in fighting against the viruses. As the Earth is our only home, we should work together to fight against the viruses and protect the natural environment. It ultimately benefits human beings.

\section{Declarations}

\section{Funding}

This research get support from Dr. Bailin Cong's the GEF-FAO Project (GCP/CPR/045/GFF).

\section{Conflicts of interest/Competing interests}

The authors declare no conflict/competing interests.

\section{Ethics approval}

Non-available. 


\section{Consent for publication}

We state that the submission for publication of this paper have been approved by all authors and the institutions; it is original, unpublished and is not being considered for publication elsewhere.

\section{Availability of data and material}

Most of the data are in the manuscript; and others are in the Supplimentary Materials. Thanks for the help of TinyGene Biotechnology Shanghai Co, LTD in analying some data and draw some figures.

\section{Code availability}

Non-available.

\section{Authors' contributions}

FZ wrote the paper; YH collected the raw data and draw some figures; $\mathrm{BC}$ rivised and gave financial support to this paper.

\section{References}

1. Wuhan (2021) https://baike.so.com/doc/498920-528228.html.

2. Xu Z, Chou C, Liang JY, Chou CK, Shiu CJ (2020) Pathological findings of COVID-19 associated with acute respiratory distress syndrome. Lancet Respir Med 8(4): 420-422

3. Copat C, Cristaldi A, Fiore M, Grasso A, Zuccarello P, Signorelli, SS (2020). The role of air pollution (PM and $\mathrm{NO}_{2}$ ) in COVID-19 spread and lethality: A systematic review. Environ Res 191:110-129

4. Real-time epidemic tracking analysis of COVID-19 (3rd Aug 2021) https://www.360kuai.com/mob/subject/400

5. Xie J, Teng J, Fan Y, Xie R, Shen A (2019). The short-term effects of air pollutants on hospitalizations for respiratory disease in Hefei. China Int J Biometeorol 63: 315-326

6. Wang YJ et al (2020) Four-Month changes in air quality during and after the COVID-19 lockdown in six megacities in China. Environ Sci Technol Lett 7: 802-808

7. Seo JH, Kim SJ, Lee M, Kang JI (2021) Impact of the COVID-19 pandemic on mental health service use among psychiatric outpatients in a tertiary hospital. J Affect Disorders 290: 279-283

8. Chen Q. Pan S (2020). Transport-related experiences in China in response to the Coronavirus (COVID19). Trans Res Inter Perspec 8,100246

9. Sicard P, Marco A, Agthokleous E, Feng ZZ, Xu X, Paoletti, E. Amplified ozone pollution in cities during the COVID-19 lockdown (2020) Sci Total Environ 735: 139542.

10. Wu JT, Leung KL, Leung, M (2020). Nowcasting and forecasting the potential domestic and international spread of the 2019-CoV outbreak originating in Wuhan, China: a modelling study. Lancet 395:689-897 
11. Su S (2021) Sulphur dioxide emissions from combustion in china: from 1990 to 2021 https://doi.org/10.1016/j.amsu

12. Ma S, Yao, J, Gao L, Ma X, Zhao Y (2012). Experimental study on removals of $\mathrm{SO}_{2}$ and $\mathrm{NO}_{\mathrm{X}}$ using adsorption of activated carbon/ microwave desorption. J Air Waste Manag Associ 62:1012-1021

13. Sillman S (1999) The relation between ozone, NOx and hydrocarbons in urban and polluted rural environments. Atmos Environ 33:1821-1845

14. Levitan_(2021) SARS-CoV-2 Lambda variant exhibits higher infectivity and immune resistance. bioRxiv https://doi.org/10.1101/2021.07.28.454085

15. Becker S, Soukup, JM (1999). Exposure to urban air particulates alters the macrophage mediated inflammatory response to respiratory viral infection. J Toxic Environ Health I 57: 445-457

16. Xie J, Teng J, Fan Y, Xie R, Shen A (2019) The short-term effects of air pollutants on hospitalizations for respiratory disease in Hefei. China Int J Biometeorol 63: 315-326

17. Wuhan Municipal Bureau of Ecology and Environment (17 th August 2021) http://hbj.wuhan.gov.cn

18. Tan P, Chou C, Chou C-KC (2013) Impact of urbanization on the air pollution "holiday effect" in Taiwan. Atmos Environ 70: 361-375

19. finance@china.org.cn. Delta virus transmission has doubled? Expert: the incubation period and the passage interval have been

shortened. http://finance.china.com.cn//news/20210731/5620676.shtml

20. Xinhua (13 ${ }^{\text {th }}$ July 2021). COVID-19 Delta variant spreading worldwide "at scorching pace": WHO chief. http://www.xinhuanet.com/english/2021-07/13/c_1310057228.htm

21. Xinhua (26 ${ }^{\text {th }}$ June 2021c) Chinese vaccines effective against COVID-19 Delta variant: Top epidemiologist. http://www.china.org.cn/china/2021-06/26/content_77589043.htm

22. Xinhua (29 $9^{\text {th }}$ June 2021b) COVID-19 Delta variant infections account for 20 pct of new cases in France http://www.xinhuanet.com/english/2021-06/29/c_1310034461.htm

23. Xinhua ( $3^{\text {rd }}$ August 2021d) Hubei: Nucleic acid test for all staff in Wuhan. http://www.xinhuanet.com/2021-08/03/c_1127726058.htm

24. Kimura I (2021) Ozone Pollution Grows, but It Can Be Fixed. https://www.scientificamerican.com/article/ozone-pollution-grows-but-it-can-be-fixed

25. MedSci (5th August 2021) Zhengzhou reported 85 new asymptomatic cases, five times the number of confirmed cases. Herd immunity dream shattered? https://mp.weixin.qq.com/s/PySH3kIEYvRjtpA6GIKRYQ

26. Knews (14th August 2021) Three doses of COVID-19 vaccine began in Guangzhou yesterday. https://www.163.com/dy/article/GHBQ0FI00514EGPO.html

27. Wang L, Zhao X, Xu W, Tang J, Jiang X (2016) Correlation analysis of lung cancer and urban spatial factor: based Correlation analysis of lung cancer and urban spatial factor: based on survey in Shanghai. J Thoracic Disease 8(9):9373. 
28. Chen Z, Cai J, Gao B, He B, Xie X (2017). Detecting the causality influence of individual meteorological factors on local PM2.5 concentration in the Jing-Jin-Ji region. Scientific Reports 7: 40735

29. Qiu H. et al (2018) The burden of overall and cause-specific respiratory morbidity due to ambient air pollution in Sichuan Basin, China: A multi-city time-series analysis. Environ Res 167:428-436.

30. Esworthy R (2013). Air quality: EPA's 2013 changes to the particulate matter (PM) standard. 6, 753 Congress Res Serv.

31. Wang Q, Su MA (2020) preliminary assessment of the impact of COVID-19 on environment - A case study of China. Sci Total Environ 728(1): 138915.

32. Briz-Redón Á, Belenguer-Sapiña C, Serrano-Aroca Á (2021) Changes in air pollution during COVID-19 lockdown in Spain: A multi-city study. J Environ Sci 101:16-26

33. Wyche KP, Nichols M, Parfittc P, Gregga DJ Smallbonea KL, Monksd PS (2021) Changes in ambient air quality and atmospheric composition and reactivity in the South East of the UK as a result of the COVID-19 lockdown. Sci Total Environ 755(1): 142526

34. Kerimray A (2020) Assessing air quality changes in large cities during COVID-19 lockdowns: The impacts of traffic-free urban conditions in Almaty, Kazakhstan. Sci Total Environ 730:13979

\section{Figures}



\section{Figure 1}

Changes of major pollutants from 1st Jan to 25th Mar with lockdown beginning date of 23rd Jan in Wuhan 


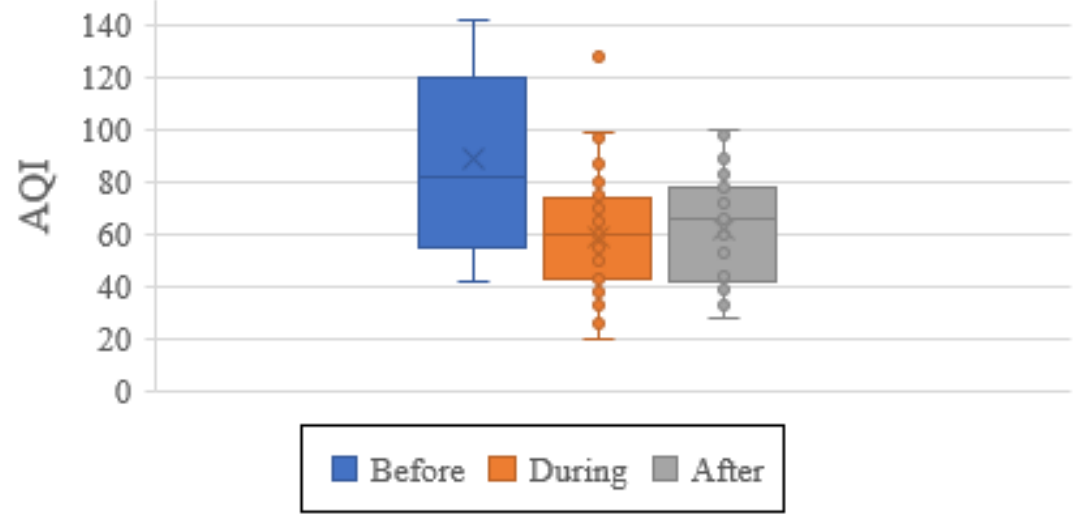

Figure 2

AQI of Wuhan in different periods: Before, during and after city lockdown

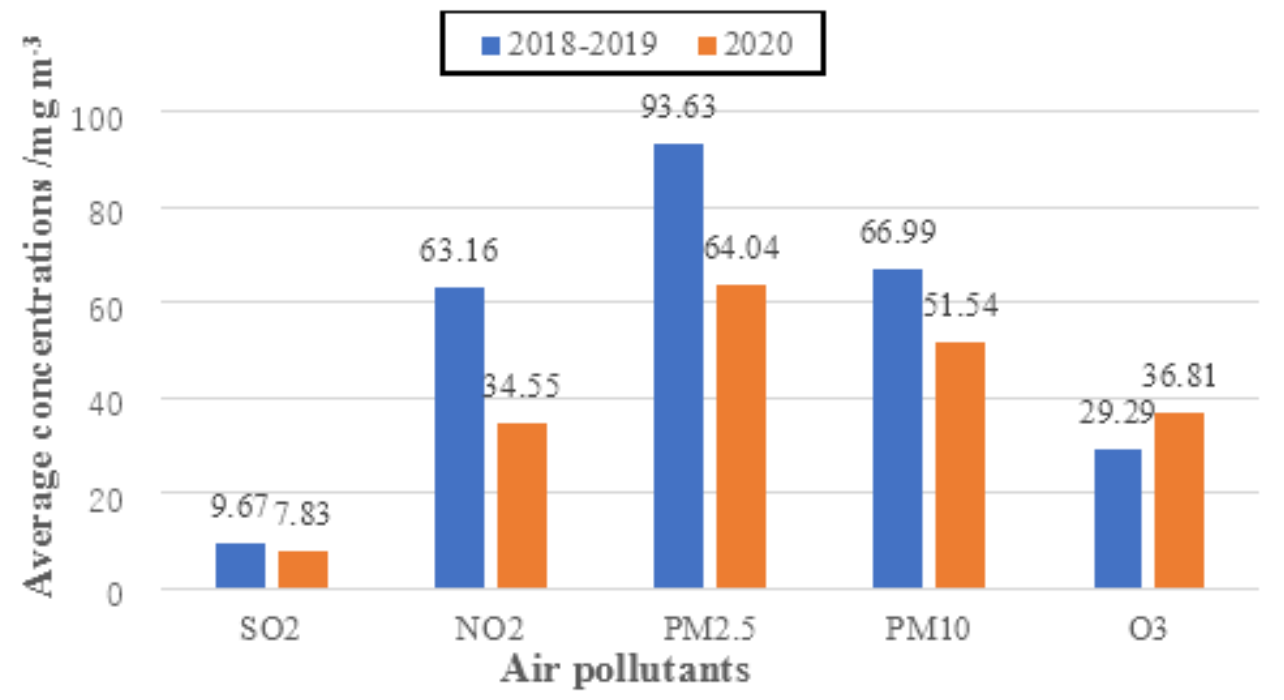

Figure 3

Concentrations of different pollutants in COVID-19 period (year of 2020) and non-COVID-19 period (year of 2018-2019) in Wuhan

\section{Supplementary Files}

This is a list of supplementary files associated with this preprint. Click to download.

- SuppimentaryMaterials.docx 